\title{
APONTAMENTOS SOBRE O ESTÁGIO SUPERVISIONADO NA FORMAÇÃO INICIAL DE PROFESSORES: A IMPORTÂNCIA DE UM ENTUSIASMO CRIITICO'
}

\author{
Matheus Bernardo Silva \\ Universidade do Sul de Santa Catarina (Unisul), Florianópolis, Santa \\ Catarina, Brasil
}

\begin{abstract}
RESUMO: O objetivo do presente texto é apresentar uma reflexão sobre o estágio supervisionado na formação inicial de professores, com a finalidade de explicitar que tal momento, no processo formativo de novos professores, contribui para que eles legitimem um entusiasmo crítico frente a sua prática de ensino, no âmbito da prática pedagógica. Trata-se de um texto de cunho teórico-bibliográfico, que buscou realizar uma análise crítica perante tal objeto de pesquisa. Como síntese, pode-se destacar que para engendrar um entusiasmo crítico no novo professor é necessário que ele possa, por meio da sua imersão na esfera escolar, estabelecer uma consciência crítico-pedagógica sobre a realidade escolar e, por meio de uma ciência da e para a educação, possa estabelecer ações pedagógicas que contribuirão tanto para a sua formação quanto para a dos alunos.
\end{abstract}

Palavras-chave: Formação de Professores. Estágio Supervisionado. Prática Pedagógica. Entusiasmo Crítico.

\section{CONSIDERAÇÕES INICIAIS}

Abordar a temática do estágio supervisionado no ambiente escolar é de fundamental importância, pois se torna o momento de reflexão sobre o direcionamento a ser dado para o futuro professor no seu principal local de atividade profissional. O presente artigo é um desdobramento de uma pesquisa do estágio de pós-doutoramento, de cunho teórico-bibliográfico, que objetiva analisar as dimensões pedagógicas que se manifestam nos cursos de licenciatura e de Pedagogia de uma determinada Universidade no estado de Santa Catarina. Para isso, foi estabelecido um recorte teórico e, por consequência, uma análise documental do movimento oriundo dos estágios supervisionados de tais cursos direcionados para a formação de professores.

Assim sendo, o intuito principal deste texto é apresentar uma reflexão sobre a necessidade de, no âmbito do processo formativo de novos professores, concretizar um entusiasmo crítico por meio de uma consciência crítica frente às demandas do atual momento da sociedade na relação com a escola (a educação escolar). A hipótese empreendida coaduna com o seguinte pressuposto: a efetividade do estágio supervisionado na esfera escolar é o momento que se articula e dá sentido às diversas atividades curriculares promovidas no âmbito dos cursos de formação de professores. E o 
sentido é, justamente, no entusiasmo crítico ao acadêmico vinculado à consciência crítica sobre a função social da escola no atual momento da sociedade.

Destarte, este texto está dividido em três momentos a seguir arrolados: 1) na caracterização, em linhas gerais, da função que deve ser atribuída à escola como determinada e determinante da atual sociedade; 2 ) na reflexão de que para que a formação de novos professores atinja seu ápice (sua finalidade), a promoção do aluno, é necessário partir de uma ciência da e para a educação (já no âmbito do estágio supervisionado), que se concretiza no âmago dos fundamentos da pedagogia na sua essência (na teoria da educação, propriamente dita); 3) por fim, na apresentação de elementos que, por meio de uma ciência da e para a educação, poderá efetivar o entusiasmo crítico no futuro professor pelo viés da consciência crítica, no qual o estágio supervisionado assume condição fulcral para tal efetividade.

\section{A ESCOLA COMO CAMPO DE ATUAÇÃO NA FORMAÇÃO INICIAL DE PROFESSORES}

Podemos apontar que é consenso e até mesmo óbvio pensar que uma formação qualificada de novos professores acarreta em impactos na esfera escolar. Isso porque o processo formativo (inicial e continuado) de professores interfere tanto nas normativas da escola quanto no processo de ensino e aprendizagem.

Destarte, para que o professor possa efetivamente contribuir para o cumprimento da principal finalidade da educação escolar, que é a promoção humana (promoção do aluno), torna-se cabal que o mesmo tenha passado por uma formação inicial coesa a partir, principalmente, da baliza de uma pedagogia (teoria da educação). Portanto, a formação de novos professores deve estar orientada teoricamente por meio de uma teoria da educação, cuja essência está na ciência da e para a prática educativa.

Porém, não basta estar balizado em uma teoria da educação se esta não estiver alinhavada com as especificidades da educação escolar, isto é, da escola. Com efeito, a escola é um valioso instrumento para o processo formativo de novos professores.

Perante tal contexto, podemos observar a importância, no âmbito das atividades curriculares, no bojo dos cursos de formação de professores que possuem uma aproximação e até mesmo uma imersão no contexto escolar. Logo, urge como necessidade compreender o espaço que a escola ocupa na esfera social.

Em linhas gerais, partimos do princípio de que a escola tem como principal enfoque o saber sistematizado, a cultura letrada, o saber científico, isto é, a cultura erudita, afastando-se, assim, daquilo que Gramsci (2001), por exemplo, chamou de folclore, de senso comum; ou como Saviani (2010) apontou como saber espontâneo, da experiência, isto é, da cultura popular. Mas, qual o motivo de apontar a escola para tal função em tempos hodiernos? Vejamos o seguinte posicionamento:

Porque o que se pode constatar é que, para desenvolver a cultura popular, não precisa da escola. Agora, na medida em que se desenvolveu uma tendência que desvaloriza ou secundariza a cultura erudita e valorizava a cultura popular e, por conta disso, passou-se a taxar a escola como alienante, como instrumento de dominação por estar ligada à norma culta, comecei a me perguntar: 
em que grau isso é realmente transformador? Cheguei inclusive a fazer frases provocativas como "sem dominar aquilo que os dominantes dominam, os dominados não chegam a se libertar da dominação". A escola seria uma forma de o homem do povo ter acesso ao saber elaborado, sem o que esse tipo de saber fica privilegio das elites. (SAVIANI, 2010, p. 167).

Para compreendermos mais detalhadamente o posicionamento de Saviani (2010) sobre o papel da escola, impera a condição de explicitar qual a natureza e a especificidade da educação escolar. Pois, dessa maneira, podemos elucidar a especificidade que a escola possui (ou deve possuir) nos dias atuais.

Portanto, partimos da premissa de que para estabelecer uma concepção de educação (sua natureza e sua especificidade) deve-se alinhavá-la com uma determinada concepção de homem, uma vez que o processo de produção da existência humana ocorre, inicialmente, para assegurar a subsistência material dos seres humanos. Como sabemos, esse processo de produção dos bens materiais se torna, no decorrer do tempo, cada vez mais amplo e complexo. Tal processo de produção é caracterizado por Saviani (2013c) como "trabalho material".

Não obstante, para que o ser humano tenha condição de concretizar o trabalho material, é necessário que antecipe no seu pensamento os objetivos e os fins da atividade material, ou seja, ele, por meio das condições dispostas pela evolução do psiquismo humano, antecipa, mentalmente, a atividade que irá realizar materialmente.

O suprassumo da atividade humana, isto é, o trabalho, depende e, ao mesmo tempo, está intrinsecamente relacionado com o conhecimento que o homem possui das propriedades do planeta (ciência), com a valoração dos dados da realidade concreta (ética) e com a simbolização de tal realidade (arte). Esses são, portanto, elementos essenciais para o constante processo de trabalho, a que se denomina "trabalho não material". Trata-se, conforme Saviani (2013c, p. 12), da "[...] produção de ideias, conceitos, valores, símbolos, hábitos, atitudes, habilidades. Numa palavra, trata-se da produção do saber, seja do saber sobre a natureza, seja do saber sobre a cultura, isto é, o conjunto da produção humana".

A natureza humana não é dada ao homem de forma instintiva ou casual. Assim sendo, o ser humano deve, de maneira consciente e intencional, produzir aquilo que a natureza não Ihe dispõe de imediato. Dessa forma, a especificidade da educação escolar se revela no trabalho educativo entendido como "[...] o ato de produzir, direta e intencionalmente, em cada indivíduo singular, a humanidade que é produzida histórica e coletivamente pelo conjunto dos homens" (SAVIANI, 2013c, p. 13). Logo, o seu objeto se dá na "[...] identificação dos elementos culturais que precisam ser assimilados pelos indivíduos da espécie humana para que eles se tornem humanos [...]" e na "[...] descoberta das formas mais adequadas para atingir esse objetivo" (SAVIANI, 2013c, p. 13).

O primeiro ponto refere-se à necessidade de identificar aquilo que é essencial, principal, fundamental que os indivíduos assimilem. Daí a importância da noção de clássico como critério para distinguir o essencial do acidental, o principal do secundário e - fundamental do acessório. Eis a necessidade de identificar o clássico dos elementos culturais, ou seja, deve-se destacar aquilo que não é necessariamente tradicional e nem moderno. Pois o clássico se distingue tanto do tradicional como do moderno, sendo 
aquilo que se tornou fundamental, essencial, portanto é o critério fundante para selecionar os conteúdos a serem tratados no decorrer do trabalho pedagógico.

O segundo ponto refere-se à formatação metodológica do trabalho pedagógico (dos conteúdos, do espaço-tempo, dos procedimentos, das estratégias, dos objetivos etc.) que será utilizada para que, de maneira progressiva, cada indivíduo, na sua singularidade, se aproprie, como uma segunda natureza, daquilo que a humanidade produziu historicamente e desenvolveu socialmente.

Como se pode perceber, a educação escolar atinge o ápice, constituindo-se na forma mais elaborada de educação. Como educação institucionalizada, a escola, além de caracterizar a especificidade da educação, assume o status de local privilegiado para evidenciar a dimensão pedagógica como mediação da prática social global.

A relação entre professor e aluno, por sua vez, é extremamente relevante, porque é por meio da mediação do professor que o aluno tem a capacidade de se apropriar das objetivações humanas. Logo, o aluno só pode se tornar um indivíduo da sua época caso ele se aproprie das referidas objetivações humanas. Tal ação não se dá de forma espontânea, mas somente por meio de processos formais e sistemáticos.

As próprias objetivações humanas na atualidade assumem, na vida dos indivíduos, aspectos construídos formalmente e de maneira sistemática. Por essa disposição, a escola é considerada a forma dominante de educação pelo fato de que é por ela, ou melhor, pela mediação do professor, em consonância com as condições objetivas disponíveis, que o indivíduo terá possibilidade de compreender a realidade concreta na sua essência. Afinal, como expõe Saviani (2015, p. 35), parafraseando a frase de Marx: "[...] a anatomia da escola é a chave da anatomia da educação".

Não se trata, conforme já assinalado, da socialização de um saber qualquer (oriundo do senso comum, da cultura popular), mas do conhecimento elaborado, do saber sistematizado e da cultura erudita: "[...] a opinião, o conhecimento que produz palpites, não justifica a existência da escola. Do mesmo modo, a sabedoria baseada na experiência de vida dispensa e até mesmo desdenha a experiência escolar, o que, inclusive, chegou a cristalizar-se em ditos populares [...]" (SAVIANI, 2013c, p. 14).

É função da escola disponibilizar as condições para que os indivíduos possam se apropriar do saber elaborado. Nesse sentido, sobre a organização do trabalho pedagógico, diz Saviani (2013c, p. 17): “Ora, clássico na escola é a transmissão-assimilação do saber sistematizado. Este é o fim a atingir. É aí que cabe encontrar a fonte natural para elaborar os métodos e as formas de organização do conjunto das atividades da escola, isto é, do currículo". O conceito abrangente de currículo é definido como a "[...] organização do conjunto das atividades nucleares distribuídas no espaço e tempo escolares. Um currículo é, pois, uma escola funcionando, quer dizer, uma escola desempenhando a função que lhe é própria" (SAVIANI, 2013c, p. 17).

De maneira ampla, porém ao mesmo tempo precisa, pode-se, neste momento, caracterizar o espaço e a função que compete à escola no bojo da sociedade atual. Tratase, portanto, de contribuir para o processo de efetivar o ser humano (o aluno) como um indivíduo do seu tempo, capaz de compreender a situação atual (momento histórico- 
social) que vive e, por conseguinte, perspectivar e realizar ações desencadeadoras que contribuam para a transformação social.

É nesse sentido que, conforme expusemos acima, a prática de ensino na esfera escolar, como um componente formativo para novos professores, é uma atividade importante que deve estar fundamentada a partir de uma ciência da e para a educação, ou seja, a partir de uma pedagogia (teoria da educação).

\title{
A PRÁTICA PEDAGÓGICA, NA ESFERA DO ESTÁGIO SUPERVISIONADO, A PARTIR DE UMA CIÊNCIA DAE PARA A PRÁTICA EDUCATIVA ESCOLAR
}

Para poder refletir sobre o estágio supervisionado de novos professores na esfera escolar, torna-se imperativa a condição de estabelecer o pressuposto de que a prática de ensino deve estar subsidiada por uma ciência da e para a prática educativa, ou seja, uma ciência da e para a educação (propriamente dita).

Isto porque, conforme dispõe Marsiglia (2017), ao se apropriar de certo posicionamento teórico e método para a prática de ensino, estipula-se um direcionamento teórico-metodológico e político-ideológico (por exemplo) em relação à prática social global (de maneira ampla) e, por conseguinte, à prática educativa escolar (de maneira restrita).

Estamos afirmando que a essência do estágio supervisionado, assim como a formação inicial de professores na sua totalidade, tem que estar fundamentada em uma pedagogia (teoria da educação), compreendida como uma ciência da e para a educação. A pedagogia, no sentido aqui atribuído, é uma ciência da prática, cuja relação teoria e prática é condição cabal para a sua essência.

Schmied-Kowarzik (1983) salienta que, justamente por essa condição fundamental da relação teoria e prática, a pedagogia

\begin{abstract}
aparece em todos os seus campos, ainda que de maneira específica: na prática da educação, sob as formas da elaboração teórica das experiências práticas, para determinar os procedimentos subseqüentes (sic.) do educador; na pesquisa da ciência da educação, nas dificuldades peculiares que surgem numa pesquisa que pretende elucidar a práxis para poder orientar a prática dos agentes; na formação de professores, nas estratégias do encadeamento de ambas - prática e pesquisa - enquanto compreensão teórica da prática e condução prática à práxis através da teoria. (SCHMIED-KOWARZIK, 1983, p. 10, grifo do autor).
\end{abstract}

Em linhas gerais, a pedagogia é uma ciência da educação compreendida e aplicada na sua essência como uma teoria dialética. Por tal caracterização, a relação entre teoria e prática torna-se fundamental para uma prática educativa que concebe a educação como mediadora da prática social global. "[...] a prática seria justamente a educação em todos os seus relacionamentos práticos, e a teoria seria a ciência da educação em suas figuras teóricas" (SCHMIED-KOWARZIK, 1983, p. 10). Destarte, a unidade teórico-prática se dá no constante processo no qual "[...] a teoria investigaria a prática sobre a qual retroagiria mediante os seus conhecimentos adquiridos" (SCHMIEDKOWARZIK, 1983, p. 10). A prática seria o ponto de início da produção do conhecimento 
e, portanto, o fio condutor da teoria, sendo esta uma prática orientada de forma coerente e coesa. "Prática e teoria, portanto, dependeriam e seriam referidas inevitavelmente uma em relação à outra" (SCHMIED-KOWARZIK, 1983, p. 10-11).

Nota-se, destarte, que a problemática pedagógica, por meio da relação teoria e prática, é o fio condutor da prática de ensino. Tal afirmação, em um sentido imediato, pode ser compreendida como óbvia; todavia, é comum estabelecer outros fios condutores da prática de ensino (da prática educativa escolar). Pois, conforme Saviani (2012), os pontos de início e de chegada do processo educativo são externos à educação. Vejamos:

Assim, as pesquisas no âmbito das ciências da educação (sociologia da educação, psicologia da educação, economia da educação, antropologia educacional, biologia educacional etc.) circunscrevem a educação como seu objeto, encarando-a como fato sociológico ou psicológico ou econômico etc., que é visto, consequentemente, à luz das teorizações sociológicas, psicológicas etc., a partir de cuja estrutura conceptual são mobilizadas as hipóteses explicativas do aludido fato. $O$ processo educativo é encarado, pois, como campo de teste das hipóteses que, uma vez verificadas, redundarão no enriquecimento do acervo teórico da disciplina sociológica (psicológica, econômica etc.) referida. (SAVIANI, 2012, p. 121).

O problema pedagógico (da prática pedagógica) se torna apenas um instrumento subordinado às distintas ciências da educação. A educação, perpetuada pelas diferentes ciências, é compreendida apenas como uma ramificação de seu objeto específico. Com efeito, no bojo da prática de ensino, no âmbito do estágio supervisionado, a atividade pedagógica do acadêmico passa a ser apenas um procedimento instrumental para aferir e compactuar com as demandas erigidas pelo foco e escopo das distintas ciências, ou seja, pelos critérios e especificidades das diferentes ciências. A prática pedagógica se torna, assim, um aspecto secundário (apenas um mecanismo).

Urge a necessidade de refletir e efetivar um movimento inverso, em que a essência está na prática pedagógica como fio condutor da prática educativa escolar. Com isso, é necessário estabelecer a pedagogia, como uma ciência da e para a educação (teoria científica da educação), cuja finalidade é sanar os problemas de cunho pedagógico, ou seja, os problemas que cercam a condição da promoção humana no aluno (a apropriação, por parte do aluno, das objetivações humanas complexas). Isto porque a pedagogia, conforme Saviani (2013a, p. 64), é "[...] uma teoria que se estrutura a partir e em função da prática educativa".

Em epítome, a condição fulcral, para a pedagogia, é o equacionamento do problema que ocorre a partir " [...] da relação educador-educando, de modo geral, ou, no caso específico da escola, a relação professor-aluno, orientando o processo de ensino e aprendizagem" (SAVIANI, 2013a, p. 64), justificando, por consequência, a prática pedagógica não como um mecanismo de aplicação de certa ciência, mas como ponto de 
partida e ponto de chegada do processo educativo, no qual a "[...] coerência e [a] eficácia é garantida pela mediação da filosofia e da teoria educacional" (SAVIANI, 2013a, p. 64-65).

As distintas ciências passam, então, a serem valiosos instrumentos na relação professor-aluno, isto é, no processo de ensino e aprendizagem. Entretanto, o conhecimento científico será utilizado a partir da problemática pedagógica, balizada, por conseguinte, pelos princípios da teoria da educação.

Assim, podemos apontar um aspecto pontual que irá contribuir para a elucidação do posicionamento enfatizado neste momento: a ciência, do ponto de vista do cientista, assume um caráter-fim; contudo, do ponto de vista do professor, a ciência assume um caráter-meio, conforme esta exemplificação:

\footnotetext{
Um geógrafo, uma vez que tem por objetivo o esclarecimento do fenômeno geográfico, encara a geografia como fim. Para um professor de geografia, entretanto, o objetivo é outro: é a promoção do homem, no caso, do aluno. Dessa forma, o conteúdo será selecionado e organizado de modo que atinja o resultado pretendido. (SAVIANI, 2013b, p. 62, grifo nosso).
}

Pode-se também ilustrar tal afirmação pelo posicionamento de Martins (2012) que, por sua vez, considera que o professor deve ter condições, na educação infantil e, portanto, perpassando pelos demais níveis da educação escolar, de incidir no desenvolvimento (na promoção) do aluno. Mas, para isso, se faz pertinente que o professor disponha de conhecimentos científicos suficientes para efetivar tal movimento no processo de ensino e aprendizagem.

Por meio dos conhecimentos científicos necessários, o professor poderá interferir de maneira indireta e direta no desenvolvimento do aluno. Entretanto, vale o seguinte adendo da autora: "[...] tal diretividade diz respeito aos conhecimentos que medeiam a atividade docente, não a atividade propriamente dita, que sempre interferirá diretamente (positiva ou negativamente) no referido desenvolvimento" (MARTINS, 2012, p. 95).

A autora intitula os conteúdos de interferência indireta como conteúdos de formação operacional. Trata-se dos conhecimentos interdisciplinares, que o professor deve ter acesso e se apropriar no seu constante processo de formação, que subjazem as diversas atividades a serem disponibilizadas aos alunos. Esses conhecimentos são oriundos do importante instrumento mencionado anteriormente: a ciência. Com efeito, são saberes psicológicos, sociológicos, biológicos etc., que não serão transmitidos, necessariamente, em suas bases conceituais, mas que, de maneira indireta, incidirá nos alunos por meio da aprendizagem.

Martins (2012) intitula de conteúdos de formação teórica os conteúdos de interferência direta. Trata-se do domínio das distintas áreas do conhecimento científico transformado em saber escolar. Esses conteúdos devem nortear as atividades propostas para os alunos em proveito de sua socialização e da apropriação das objetivações humanas.

Os conteúdos de formação operacional interferem diretamente na constituição de novas habilidades na criança [no aluno], mobilizando as funções inatas, os processos psicológicos elementares, tendo em vista a complexificação de sua estrutura e de seus modos de 
funcionamento, a serem expressos sob formas de funções culturais, de processos psicológicos superiores. Ao atuarem nessa direção, instrumentalizam a criança [o aluno] para dominar e para conhecer os objetos e os fenômenos do mundo à sua volta, isto é, exercem uma influência indireta na construção de conceitos.

Os conteúdos de formação teórica, por sua vez, operam-se indiretamente no desenvolvimento das funções psicológicas, à medida que promovem a apropriação do conhecimento. Por exemplo, o ensino do conteúdo Formas Geométricas a uma criança [aluno] não contém apenas a aprendizagem de uma propriedade matemática, pois ele também incide sobre os processos de percepção, atenção, memória, linguagem etc. (MARTINS, 2012, p. 9697, grifos do autor).

Observa-se, então, a importância das ciências para o processo educativo escolar. Todavia, tais ciências são subordinadas às demandas erigidas pela prática pedagógica. A atividade pedagógica se legitima, dialeticamente, no cômputo das ações educacionais do professor em proveito da formação humana do aluno para que ele tenha condições de aprofundar a sua compreensão da realidade concreta, isto é, da prática social global.

\section{A FORMAČ̃̃ DE NOVOS PROFESSORES EM PROVEITO DE UM ENTUSIASMO CRÍTICO NO ÂMBITO DA PRÁTICA PEDAGÓGICA NA EDUCAÇÃO ESCOLAR: A IMPORTÂNCIA DO ESTÁGIO SUPERVISIONADO}

A menção, neste momento, à formação inicial de professores em proveito de um entusiasmo crítico, não se destina necessariamente à compreensão de uma formação profissional de maneira romântica e descontextualizada da condição histórico-social, mas, ao contrário, estamos nos referindo ao propósito concreto que compete ao professor na situação atual da nossa sociedade. Esse entusiasmo crítico tem sua gênese, principalmente, na formação inicial de professores, cuja manifestação da prática de ensino se dá, em nossa compreensão, nas atividades acadêmicas oriundas do estágio supervisionado.

Na especificidade do estágio supervisionado como contribuinte para a formação sistematizada de novos professores em proveito de um entusiasmo crítico ocorre a necessidade de efetivá-lo para além de cumprir apenas as demandas quantitativas (carga horária, por exemplo), predominantes na essência do estágio supervisionado na atualidade. Compactuamos, então, com o seguinte posicionamento de Almeida (2016, p. 206):

Se na formação de professores [...] os estágios curriculares forem experiências que possibilitem a construção e desconstrução da prática docente quantas vezes forem necessárias, e não apenas o cumprimento rotineiro de determinada carga horária, estes podem ser um procedimento valioso para colaborar, juntamente com as demais disciplinas do currículo, para uma preparação profissional efetiva. Uma preparação profissional que, certamente, terá 
repercussões na educação como um todo, dado que os professores são o espírito e o coração para qualquer proposta de melhoria da educação escolar.

Portanto, para atingir o ápice da reflexão de Almeida (2016), é cabível legitimar o processo educativo, como já anunciado, como um critério, ou seja, "[...] que a incorporação desse ou daquele aspecto do acervo teórico que compõe o conhecimento científico em geral dependerá da natureza dos problemas enfrentados pelos educadores" (SAVIANI, 2013b, p. 112).

Nesse sentido, o futuro professor, na sua prática de ensino no estágio supervisionado, terá condições de se afastar de uma atividade pedagógica fundamentada pela curiosidade, ou seja, pelos fatos acidentais (SAVIANI, 2011). Tal indivíduo, no bojo do seu processo formativo, ao se apropriar dos conhecimentos científicos necessários para a atividade pedagógica, passará a não realizar uma atividade a partir da tentativa e erro, ou seja, não realizará a atividade pedagógica por meio das manifestações fenomênicas aparentes (originária pelas intuições do indivíduo).

O acadêmico, como um futuro professor, terá condições de se apropriar, por exemplo, da técnica para executar suas ações na prática de ensino. Sendo a técnica compreendida aqui, grosso modo, como um conjunto de regras sistematizadas que indicam a maneira de proceder em determinadas atividades. Com efeito, aquilo que o acadêmico se apropria no decorrer do seu processo formativo (na sua formação inicial), acarretará em um conjunto de técnicas apropriadas por ele, que são, por sua vez, derivadas do conhecimento científico.

Todavia, vale um adendo: a técnica que estamos mencionando não se aproxima do preceito de uma pedagogia tecnicista, a qual se legitima pela produtividade e pela neutralidade científica no processo educativo, mas compreendendo, numa acepção gramsciana, que "a técnica é 'o meio de mediação entre o homem e a realidade" e efetivamente o homem "não entra em relações com a natureza simplesmente pelo fato de ser ele mesmo natureza, mas ativamente, por meio do trabalho e da técnica" (BOOTHMAN, 2017, p. 767).

A técnica contribui para compreender a realidade concreta e nela poder intervir de forma sistemática. O professor, para desenvolver sua função pedagógica na totalidade, há de se apropriar dos conhecimentos científicos pertinentes à sua atividade. $\mathrm{E}$, nesse tocante, as técnicas tornam-se instrumentos pertinentes para pensar a maneira de organizar e realizar a atividade pedagógica sistematizada.

Destarte, à guisa de ilustração, os conhecimentos científicos oriundos da psicologia não assumem o caráter-fim da prática pedagógica, mas o caráter-meio, pois a compreensão, por parte do professor, da periodização do desenvolvimento psíquico do aluno, não é a finalidade da prática pedagógica, mas um meio para que o professor tenha condições de interferir qualitativamente nesse desenvolvimento, a partir do processo de ensino e aprendizagem. Então, a psicologia, assim como a sociologia, a antropologia, a biologia etc. tornam-se elementos pertinentes para contribuir no problema que se estabelece na constante relação entre professor e aluno.

Cabe então ao acadêmico, como futuro professor, na sua prática de ensino no estágio supervisionado, concretizar tais premissas e executar suas ações pedagógicas no sentido de estabelecer um estofo teórico-prático na sua legitimidade como professor. Eis 
aí a importância desse processo formativo ser substanciado por uma consciência críticopedagógica, cujo intuito é efetivar um entusiasmo crítico no acadêmico.

Esse entusiasmo crítico, que difere de um entusiasmo romântico e ingênuo, se dá ao compreender que a educação não é um fenômeno afastado (autônomo) do meio social, mas que é determinada e determinante da sociedade na qual está inserida. Portanto, é cabal que a prática pedagógica atenda somente a um dos dois posicionamentos sociais que engendram a atual sociedade: que trilhe ao encontro do atual projeto social ou que trilhe de encontro do atual projeto social.

A criticidade aqui enfatizada supõe que o professor atenda ao segundo posicionamento social, isto é, que compreenda os movimentos que regem a hodierna sociedade e, por consequência, apresente elementos que contribuam para sua transformação social. Portanto, a formação de novos professores deve promover ações desencadeadoras em proveito da passagem da consciência ingênua da realidade concreta para a consciência crítica. Essa passagem necessária irá permitir que o futuro professor possa compreender a educação como um fenômeno condicionado e que é ilusório pensar que a realidade irá mudar pelo advento ou pelo poder da sua ação subjetiva.

Na medida em que descobre que a educação é um fenômeno condicionado, determinado pelo modo de produção, pela estrutura da sociedade, pela correlação de forças, pelo controle político exercido por meio da dominação e hegemonia, esboroa-se toda aquela ilusão de poder. (SAVIANI, 2014, p. 45).

Porém, pode ser que o futuro professor, ao constatar tal fato ilusório, transcenda para um pessimismo que, seguindo diç̧ão de Saviani (2014), se caracteriza também como ingênuo, pois passa a compreender agora que o projeto social atual, oriundo da classe dirigente, é tão intenso, que não há condição de a educação contribuir de maneira positiva para a transformação social. É justamente na passagem para a consciência crítica que é possível superar o posicionamento ingênuo tanto positivo (otimismo) como negativo (pessimismo), concretizando no futuro professor um entusiasmo crítico. Fazemos valer, novamente, a importante reflexão de Saviani (2014):

Entretanto, se a consciência dos condicionantes objetivos, ao mesmo tempo em que destrói o poder fictício, constrói um poder efetivo, então resulta possível superar seja o otimismo ingênuo, seja o pessimismo também ele ingênuo, em direção àquilo que eu chamaria de entusiasmo crítico. (SAVIANI, 2014, p. 45-46, grifo do autor).

Podemos verificar a importância que a formação de professores possui na legitimação de uma consciência crítica, que se converta em um entusiasmo crítico dos novos professores. Para que isso se efetive, há a necessidade de um estágio supervisionado qualificado que tenha como essência uma relação qualitativa entre teoria e prática a partir de uma teoria da educação crítica (pedagogia crítica), como uma ciência 
da e para a educação (para a prática educativa). Dessa forma, a prática de ensino no estágio supervisionado tornar-se-á um espaço privilegiado para compreender, por parte do acadêmico, que espaço é a escola e a importância da educação sistematizada em proveito da transformação social. Ademais, é somente se penetrando pelas sendas da escola que o acadêmico poderá consubstanciar uma consciência crítica, configurando, na sua plenitude, um entusiasmo crítico.

Aí nós ganhamos, enfim, a possibilidade de abraçar apaixonadamente a causa da educação, assumindo o compromisso de lutar pelas condições objetivas nas quais se converterá em verdade prática o processo de formação humana que nos trará a suprema alegria de ver, com a contribuição do nosso trabalho educativo, as crianças, todas as crianças, crescerem em graça e sabedoria diante de si mesmas e de toda a humanidade (SAVIANI, 2014, p. 46, grifo nosso).

Ora, em suma, não há outra maneira senão fazer com que o acadêmico (o futuro professor) adentre no espaço escolar com essa condição de perspectivar e efetivar ações pedagógicas qualificadas, a fim de contribuir na promoção dos alunos, ou seja, no processo de formação humana em um sentido integral, cuja essência será contribuir para que o aluno possa se apropriar do universal (das objetivações humanas) em sua singularidade, por intermédio do particular. E nisso, no tocante ao processo inicial da relação do futuro professor com a escola (a educação escolar), o estágio supervisionado assume total condição, desde que esteja formulado para atender essa rica possibilidade ao acadêmico.

\section{CONSIDERAÇÕES FINAIS}

O presente texto buscou apresentar uma reflexão sobre a importância do estágio supervisionado na formação de novos professores. Com efeito, identificamos que tal importância se dá na possibilidade de encaminhar o futuro professor para o seu espaço de atuação, ou seja, a escola. A partir dessa constatação, foi possível destacar determinados elementos que, a nosso ver, são fundamentais para que o futuro professor possa compreender concretamente a sua função social na esfera escolar. Tomando como princípio que o papel da educação escolar é a promoção do ser humano (do aluno), urge a necessidade do professor estabelecer mecanismos e instrumentos para contribuir nessa demanda da educação escolar.

Portanto, a contribuição do professor se dará somente se ele tiver consolidado um entusiasmo crítico sobre a sua prática profissional (sua prática de ensino). Logo, a prática pedagógica, consubstanciada por uma consciência crítica do professor, irá gerar ações desencadeadoras nos alunos, cujo intuito será fazer com que eles possam se tornar indivíduos do seu tempo (conhecedores da situação atual da sociedade) e, por consequência, possam perspectivar e contribuir para a transformação social.

É com esse entusiasmo crítico, por meio de uma consciência crítica, que o futuro professor terá que se legitimar no decorrer do seu processo formativo. Com isso, a escola, via estágio supervisionado, torna-se espaço primordial para que esse novo professor se legitime como um indivíduo crítico, isto é, como um indivíduo que tenha um entusiasmo 
crítico frente a sua função perante a educação escolar, perante a promoção humana no humano (no aluno).

\section{APPOINTMENTS ON SUPERVISED INTERNSHIPIN INITIAL TEACHER TRAINING: THE IMPORTANCE OF CRITICAL ENTHUSIASM}

ABSTRACT: The aim of the present text is to present a reflection about the supervised internship in the initial formation of teachers, with the purpose of explaining that this moment, in the formative process of new teachers, helps them to legitimize a critical enthusiasm towards their teaching practice, within the scope of pedagogical practice. It is a theoretical-bibliographic text, where it sought to perform a critical analysis of this research object. As a synthesis it can be emphasized that to generate a critical enthusiasm in the new teacher it is necessary that the teacher can, through his immersion in the school sphere, establish a critical-pedagogical consciousness about the school reality and, through a science of e for education, can establish pedagogical actions that will contribute both to their training and to that of schoolchildren.

KEYWORDS: Teacher training. Supervised internship. Pedagogical Practice. Critical Enthusiasm.

\section{NOTAS SOBRE LA ETAPA SUPERVISADA EN LA FORMACIÓN INICIAL DE PROFESORES: LA IMPORTANCIA DE UN ENTUSIASMO CRÍTICO}

RESUMEN: El objetivo del presente texto es presentar una reflexión sobre el estadio supervisado en la formación inicial de profesores, con la finalidad de explicitar que tal momento, en el proceso formativo de nuevos profesores, contribuye a que los mismos legitimen un entusiasmo crítico frente a su práctica de enseñanza en el ámbito de la práctica pedagógica. Se trata de un texto de cuño teórico-bibliográfico, donde buscó realizar un análisis crítico ante tal objeto de investigación. Como síntesis se puede destacar que para engendrar un entusiasmo crítico en el nuevo profesor es necesario que el mismo pueda, por medio de su inmersión en la esfera escolar, establecer una conciencia crítico-pedagógica sobre la realidad escolar y, por medio de una ciencia de la y, para la educación, pueda establecer acciones pedagógicas que contribuirán tanto para su formación como para la de los alumnos escolares.

PALABRAS CLAVE: Formación de profesores. Etapa Supervisada. Práctica pedagógica. Entusiasmo Crítico.

\section{NOTA}

1) Este artigo teve como fonte de financiamento a CAPES, via Programa Nacional de Pós-Doutorado (PNPD). 
SILVA, M. B.

\section{REFERÊNCIAS}

ALMEIDA, J. S. A formação de professores em São Paulo (1846-1996): a prática de ensino em questão. Campinas: Autores Associados, 2016.

BOOTHMAN, D. Técnica. In: LIGUORI, G.; VOZA, P. (orgs.). Dicionário gramsciano (19261937). São Paulo: Boitempo, 2017. p. 767.

GRAMSCI, A. Cadernos do Cárcere: Os intelectuais; O princípio educativo; Jornalismo. vol. II. 2. ed. Rio de Janeiro: Civilização Brasileira, 2001.

MARSIGLIA, A. C. G. Elementos históricos acerca da didática: do ratio studiorum à didática pós-moderna. Revista Teoria e Prática da Educação, Maringá, v. 20, n. 02, p. 0318, mai./ago. 2017.

MARTINS, L. M. O ensino e o desenvolvimento da criança de zero a três anos. In: ARCE, A.; MARTINS, L. M. (orgs.). Ensinando aos pequenos de zero a três anos. Campinas: Alínea, 2012. p. 93-122.

SAVIANI, D. Interlocuções pedagógicas: conversa com Paulo Freire e Adriano Nogueira e 30 entrevistas sobre educação. Campinas: Autores Associados, 2010.

SAVIANI, D. Educação em diálogo. Campinas: Autores Associados, 2011.

SAVIANI, D. A pedagogia no Brasil: história e teoria. 2. ed. Campinas: Autores Associados, 2012.

SAVIANI, D. Aberturas para a história da educação: do debate teórico-metodológico no campo da história ao debate sobre a construção do sistema nacional de educação no Brasil. Campinas: Autores Associados, 2013a.

SAVIANI, D. Educação: do senso comum à consciência filosófica. 19. ed. São Paulo: Autores Associados, 2013b.

SAVIANI, D. Pedagogia histórico-crítica: primeiras aproximações. 11. ed. rev. Campinas: Autores Associados, 2013c.

SAVIANI, D. O lunar de sepé: paixão, dilemas e perspectivas na educação. Campinas: Autores Associados, 2014.

SAVIANI, D. O conceito dialético de mediação na pedagogia histórico-crítica em intermediação com a psicologia histórico-cultural. Revista Germinal:marxismo e educação em debate, Salvador, v. 07, n. 01, p. 26-43, jun. 2015.

SCHMIED-KOWARZIK, W. Pedagogia dialética: de Aristóteles a Paulo Freire. São Paulo: Brasiliense, 1983. 
Apontamentos sobre o estágio supervisionado...

Matheus Bernardo Silva: Pós-Doutorando em Educação pela UNISUL. Doutor em Educação pela UNICAMP. Mestre em Educação pela UFPR. Licienciado em Educação Física pela UNESC.

Orcid: http://orcid.org/0000-0002-5964-368X

E-mail: matheusbernardo25@gmail.com

Este periódico utiliza a licença Creative Commons Attribution 3.0, para periódicos de acesso aberto (Open Archives Iniciative - OAI). 